\title{
TIRSO DE MOLINA, INDIOS Y ENCOMENDEROS
}

POR

\author{
CEFERINO CARO LÓPEZ
}

\begin{abstract}
En la Trilogía de los Pizarro hay elementos que permiten afirmar que el dramaturgo usó un encargo ocasional para hacer un instrumento de crítica de la política de su tiempo, poniendo en evidencia la figura de los validos y de los malos consejeros. Contra las novedades introducidas en el gobierno y en la política indiana Tirso proponía la abolición de las medidas humanitarias incluidas en las Leyes Nuevas y el fortalecimiento de la autoridad de los encomenderos. La Trilogía se presenta por lo tanto como un ejemplo del cambio cultural entre el erasmismo del Renacimiento y la crisis de la Contrarreforma.
\end{abstract}

Todo es dar en una cosa, Amazonas en las Indias y La lealtad contra la envidia forman la llamada Trilogía de los Pizarro de Tirso de Molina, escrita hacia 1626 con el fin de reivindicar el buen nombre del fundador de esa familia y la confirmación del título de Marqueses de la Conquista ${ }^{1}$. Por esas fechas Tirso estaba en Trujillo, adonde había sido mandado a causa de ciertas desavenencias ideológicas con otros literatos, aunque R.L. Kennedy menciona que también hubo algunos problemas con la Corona y Olivares a propósito de ciertas tentativas de reforma de la orden de la Merced. Sobre este punto concreto es difícil encontrar un apoyo firme para explicar la antipatía del dramaturgo, porque la política del conde-duque se ca-

1 La edición seguida es la de M. Zugasti, Tirso de Molina, Trilogía de los Pizarros, Kassel 1993, con importante estudio crítico, que se citará siempre. Sobre esta comedia, véase también O.H. GREEN, "Notes on the Pizarro Trilogy of Tirso de Molina", Hispanic Review, IV, 1936; A.B. DellePIANE, "Ficción e historia en la Trilogía..." Filología, 4, 1952-1953; S. MAUREL, L'Univers dramatique de Tirso de Molina, Poitiers 1971, pp. 142 ss. y 371 ss; R.L. KENNEDY, Estudios sobre Tirso, Madrid 1983; T. FERNÁNDEZ, "La imaginación americana en el teatro de Tirso de Molina", Edad de Oro, X, 1991. 
racterizó por una gran cautela para con los religiosos ${ }^{2}$. Sin embargo es insoslayable referirse al ambiente político de los años veinte del siglo XVII para comprender las razones objetivas y subjetivas del dramaturgo en su inquina para con el valido. La llamada Junta Grande de Reformación lanzada por el conde-duque en 1622, que habría supuesto grandes cambios en la administración del reino, recibió desde un principio una fortísima oposición social, precisamente por lo que introducía de novedad en un ambiente ya sensibilizado tras el mal gobierno de Lerma ${ }^{3}$. Personalmente, además, Tirso se había enemistado con un pariente del valido, fray Pedro de Guzmán, hermano suyo de hábito ${ }^{4}$. En el plano literario también Tirso estaba empeñado en una lucha con - o contra - Hurtado de Mendoza, pero detrás de ese autor estaban el conde-duque y la Junta de Reformación, lo que hace plausible pensar que la polémica tuviera connotaciones políticas antes que estéticas. La oposición de Tirso al valido, nunca ocultada, se alimentaba de convicciones políticas profundas y discrepantes hasta el punto de que en la Historia de la orden de la Merced que escribió en 1638 el dramaturgo comparaba la situación de España en tiempos de Felipe III con la suya actual, y el resultado era desfavorable para sus coetáneos: se trata de un análisis político exactamente opuesto al que el conde-duque realizaba en su gran memorial de reforma presentado a Felipe IV en 1625, en el que veía una decadencia continua de España desde los Reyes Católicos hasta Felipe III, momento en que había tocado su punto más bajo. Dado que también otros estudiosos han puesto en luz la tensión existente entre el fraile mercedario y el Poder, parece muy justifica-

2 KENNEDY [1], pp. 16-17 y 46; J.H. ElliotT, El Conde-duque de Olivares, Barcelona, 1996, p. 196.

3 J.H. ElliotT, "El programa de Olivares y los movimientos de 1640", Historia de España, dir. JOVER ZAMORA, XXV, Madrid, 1996 pp. 343 y ss. Es imprescindible el estudio sobre el Conde-duque del mismo autor, citado en la nota anterior, para enmarcar la situación de fervor político de la época. Tirso, en cuanto religioso, podía sentirse amenazado por el planteamiento regalista de Olivares y su política de tributación extraordinaria de 1624 (Conde-duque [2], pp. 166-168).

4 ElliotT, [2], p. 189; el episodio se narra en la introducción de M. PinEdo ReY, O.M, a TIRSO DE MOLINA, Historia General de la Orden de Nuestra Señora de las Mercedes, I, Madrid, 1973, pp. LXXX y ss. También J.H. ELLIOTT, "Poder y propaganda en la España de Felipe IV”, España y su mundo 1500-1700, Madrid, 1991, y J.A. MARAVALL, La oposición política bajo los Austrias, Barcelona, 1974.

R.I., 1997, n. $^{\circ} 210$ 
da la pretensión de ver la Trilogía no como una obra literaria inocente sino como un tex to cargado de intencionalidad política.

De las tres comedias de la Trilogía era seguramente la segunda, Amazonas en las Indias, la más declaradamente política, porque su tema consistía en la difícil tarea de disculpar a un acusado de rebelión y traición a su rey, y es en esta obra donde habrá que encontrar las tomas de posición más decididamente políticas, de manera que descodificando el metatexto ideológico de la comedia se pueda alcanzar el verdadero objetivo del autor. En el caso de que este análisis sea el correcto, se podrá afirmar desde ahora que, al aceptar el encargo ocasional de los descendientes de los Pizarro, Tirso de Molina llevó a cabo no solo la glorificación de los conquistadores, sino que escribió un durísimo alegato contra la política reformista americana de Carlos V y consiguió conectarlo, en su crítica, con el modo de gobernar del conde-duque de Olivares.

\section{LA CRÍTICA DE LA POLÍTICA INDIANA EN LA TRILOGÍA.}

En Amazonas en las Indias Carvajal, compañero de fatigas de Gonzalo Pizarro, exclamaba lamentando la política del Emperador:

\author{
Podrán los conquistadores \\ aprender de oy más oficio, \\ y en pago de sus hazañas \\ pedir limosna sus hijos. \\ Todo esto ocasiona el zelo \\ de escrupulosos caprichos, \\ todo esto inventan ociosos, \\ todo esto causan arbitrios. \\ (1914-1921).
}

El personaje tirsiano no paraba en barras al protestar por la política del emperador: escrupulosos caprichos, arbitrios, inventos de ociosos, habían conseguido que los conquistadores tuvieran que aprender un oficio manual - perspectiva horrible - si no querían que sus hijos se vieran obligados a la mendicidad. Pero ¿qué eran en realidad esos ominosos arbitrios cuyas consecuencias criticaba tan duramente? Carvajal se refería a las llamadas Leyes Nuevas y por 
ende a las medidas tomadas por Carlos $\mathrm{V}$ para normalizar la conquista del Nuevo Mundo.

Efectivamente, poco después de la Conquista empezó a manifestarse lo que López Alonso y Elorza han llamado "la insólita mala conciencia" de los españoles 5 , ya desde el famoso sermón de Montesinos de 1511. Sin embargo es necesario precisar que Montesinos, aun criticando la crueldad y la codicia de los castellanos, condenaba la Conquista en cuanto que no había sido autorizada con los debidos permisos, y por lo tanto para él no era injusta desde el punto de vista de lo que luego se daría en llamar derecho de gentes, sino desde el que se derivaba de los abusos de la encomienda ${ }^{6}$. El discurso crítico era, en realidad, el del gattopardo: cambiarlo todo para que todo siguiera igual, al poner el acento en las mejores condiciones del trato para con los indios pero dejando por sentado que los europeos, ya instalados sólidamente en el Nuevo Mundo, deberían ser los amos de la humanidad que se les brindaba en tutela.

Lo más característico en el debate teórico español en el siglo XVI sobre las relaciones entre Viejo y Nuevo Mundo fue el deslizamiento de los aspectos políticos a las consideraciones morales, porque la mayoría de los pensadores contemporáneos de la Conquista - y muchos entre los críticos actuales - se centraban antes en el deber ser subjetivo que en la realidad objetiva de la historia ${ }^{7}$, cosa muy comprensible porque de esa manera se podía plantear el problema en base a consideraciones sobre el valor de la utopía humanístico-humanitaria y de la evangelización de las Indias en cuanto justificaciones del proceso de la Conquista: el punto realmente en discusión era el de la práctica de la encomienda y su alcance, tanto jurídico, político y económico como ético.

La encomienda era una institución cuyo fin declarado debía ser el de asegurar a los indios protección, enseñanza e inserción en la

5 LóPEZ Alonso-EloRZA, El hierro y el oro, Madrid, 1989, p. 37. Véase también Ch. VERLINDEN, "Las reducciones y los cambios estructurales en el México hispano(siglos XVI-XVII)" Revista Complutense de Historia de América, 20, 1994. Un estudio magnífico es el libro de S. CRO, Realidad y utopía en el descubrimiento y Conquista de la América hispana, (1492-1682), Madrid, 1983; también interesante V. FRANKL, El "Antijovio" de Gonzalo Jiménez de Quesada, Madrid, 1963.

6 García Garcia, "La ética de la Conquista en el pensamiento español anterior a 1534", La Ética en la Conquista de América (1492-1573), Salamanca, 1984, pp. 77-78.

7 Un ejemplo reciente es el de B. FERNÁNDEZ HERRERO, La utopía de la aventura americana, Barcelona, 1994.

R. I., 1997, n. ${ }^{\circ} 210$ 
nueva organización social y económica que los españoles estaban introduciendo en América y a la que, a todas luces, se los consideraba incapaces de adaptarse por sí solos. Con esa práctica un número variable de familias indígenas se daba en tutela - se encomenda$b a$ - a la protección de un español -el encomendero ${ }^{8}$. Los pasos en el proceso de sometimiento de los indígenas son de sobra conocidos, desde 1503, cuando una Real Cédula concedía en la práctica una "ilimitada explotación" del nativo según Fernández Herrero", abuso tal que dio lugar a las denuncias de Montesinos, y que fue la ocasión para el debate en la corte de Castilla. A raíz de ello se promulgaron las Leyes de Burgos en 1512, para permitir la encomienda no en su forma de explotación del trabajador sino en la que se presenta tradicionalmente de tutela de un individuo considerado minus habens intelectual, pero el carácter puramente teórico de estas medidas, que sólo tendían a enmascarar la realidad y no a corregirla, se demuestra claramente ya que los dominicos siguieron criticando la situación y consiguieron que se promulgaran las Leyes Nuevas en 1542. Puesto que había sido imposible abolir el sistema de la encomienda -a causa de su fundamento económico- al menos se intentaba paliar su dureza. De tal manera que se llegó a la Junta de Valladolid en la que tuvo lugar la controversia entre Las Casas y Sepúlveda, en 1550, y en esta ocasión fue suprimida otra práctica que parecía servir para justificar la Conquista de los españoles, el requerimiento. Era éste un mecanismo que arrancaba de la admisión sin reservas de la donación papal con las bulas Inter Caetera y el Tratado de Tordesillas, y partía de consideraciones teológicas acerca de la unidad del género humano, por lo que imponía de hecho la obligación de evangelizar a

\footnotetext{
8 J. GonZÁLEZ RodríGUEZ, "Planteamiento oficial de la crisis: la Junta de Valladolid y la supresión de la Conquista (1549-1556)", La Ética en la Conquista... [6], p. 273; L. PEREÑA VICENTE, "El concepto de derecho de gentes en Francisco de Vitoria", Revista Española de Derecho internacional, I, 1952; H. TANZI, "La doctrina de los juristas hispanos sobre el Poder político y su influencia en América", Boletín Histórico, 24, 1970; M. LUCENA, "Crisis de la conciencia nacional: las dudas de Carlos V", La Ética en la Conquista... [6]; F. Murillo RUBiERA, "La Conquista de América y el Derecho de gentes", La Ética de la Conquista... [6]; S. ZAVALA, La defensa de los derechos del hombre en América Latina (siglos XVI-XVII, UNESCO, 1963, y La filosofía política en la Conquista de América, México 1984; R. GARCía CÁRCEL, La leyenda negra, Madrid 1992; SÁNCHEZ BELlA, DE la Hera, Díaz ReMENTERIA, Historia del derecho indiano, Madrid 1992; FernáNDEZ HERRERO, [7], pp. 162 y ss.

9 FERNÁNDEZ HERRERO, [7], p. 170.
} 
los pueblos conquistados. El requerimiento se ideó para establecer las relaciones entre gobernantes y gobernados, y en el fondo era un ultimátum que se daba a los indios: o aceptaban espontánea y pacíficamente las leyes de los blancos, o se los podía someter por la fuerza; pero en ambos casos el resultado era bastante parecido. Que el requerimiento fuera una práctica insostenible desde el punto de vista moral y jurídico lo demuestran no sólo los crueles sarcasmos de los contemporáneos sino también la cantidad de ocasiones en que fue abolido: primero en 1542, a los quince años de que lo confirmaran, y de nuevo en 1550, aunque "de manera explícita no desapareció hasta las Ordenanzas de $1573^{10}$.

De modo que toda la discusión y la Duda Indiana giraron siempre en torno al problema de la relación con los indígenas, pero sin poner nunca en tela de juicio el que los españoles eran los justos amos de las tierras descubiertas por Colón. En 1512 Palacios Rubios había supeditado la libertad de los indios a su aceptación de la fe católica, y en caso de resistencia el monarca castellano hubiera podido privar a los rebeldes de todos sus derechos, aplicando los más duros principios del requerimiento. Pero en Burgos ante Palacios se había oído también la voz del dominico Matías de Paz, sosteniendo un punto de vista diametralmente contrario, pues según éste la licitud de la Conquista dependería de la manera en que se hubiera tratado a los nativos:

\footnotetext{
"siempre que se les govierne no con despótico sino con real principado, y se les considere como hijos y hombres libres, rescatados con la sangre preciosísima del Redentor de todos".
}

Así, la Conquista se juzgaría y justificaría por sus efectos, mientras que para las posturas oficiales más cercanas al poder la justificación era a priori.

Por lo tanto, el debate sobre la Conquista se bifurcó bien pronto en una disyuntiva irreconciliable, a saber la del interés por la organización y la administración del territorio —en suma, imperialista- y

\footnotetext{
10 GARCía CÁRCEL, [8], p. 223; cfr. también D. RAMOS, "Las Conquistas americanas anteriores a 1534, a la luz de la ética oficial", La Ética en la Conquista... [6]; Historia General de España y América, vols. VII y IX-1, Madrid, 1982; C.M. GASTEAZORRO RODRíGUEZ, "Las grandes Conquistas", Historia general de España y América, VII, Madrid, 1982.
}

R. I., $1997, \mathrm{n}^{\circ} 210$ 
la que ponía el acento en la responsabilidad de los conquistadores para con los nativos. Tanto es así que en la Junta de Valladolid se aceptaron las tesis de Vitoria, eminentemente jurídico-políticas pero no sin deslizamientos sensibles ${ }^{11}$. Por último, en la Ordenanza de 1573 se eliminaba prácticamente el requerimiento a la vez que el término mismo de Conquista era sustituido por el de Pacificación. Esta segunda medida era claramente el resultado de las guerras araucanas pero, al extenderse a todo un período histórico, demuestra que se había realizado una relectura completa de la empresa americana en clave política. Con el uso de la nueva terminología se marcaba la pauta para el planteamiento oficial de lo que en adelante habría de ser la visión autorizada de la intervención española en el Nuevo Mundo: el haber llevado la paz y el Evangelio a los pueblos americanos. El carácter meramente ideológico de esta actitud ante la realidad histórica queda de manifiesto por el hecho de que la prohibición efectiva de hacer guerra a los nativos fue sancionada solamente con la ley 9, título 4, libro III de la Recopilación de las Leyes de Indias de $1680^{12}$, por lo que nos hallamos ante un ejemplo evidente de doble lenguaje, con el que el Poder maquillaba la realidad por medio del razonamiento ideológico concebido sobre todo con fines propagandísticos.

Precisamente la naturaleza ideológica y propagandística del discurso del Poder nos brinda la conexión con la obra literaria tirsiana de la que hemos arrancado, pues una vez fijada, mediante la controversia y la producción teórica política, la posición oficial ante la Conquista, se presentaba el problema de hacer que la sociedad en su conjunto la aceptara. Así que ahora la función principal correspondía a los intelectuales orgánicos, a los literatos del Siglo de Oro, sobre todo

11 FR. M. DE PAZ, O.P, Del dominio de los reyes de España sobre los Indios, México, ed. S. Zavala, 1954; García Y GARcía, [6], p. 83; J. LóPEZ DE PAlacios Rubios, De las Islas del Mar Océano, México, ed. S. Zavala, 1954, pp. 25, cap. 3 y pp. 128 y ss. y 149 y ss. Sobre Palacios Rubios, véase J. DE LA FUENTE, "Palacios Rubios. Su importancia jurídica, política y literaria", Revista General de legislación y Jurisprudencia, 1869-1870; LóPEZ Alonso-ElorZA, [5], p. 59. Sobre Vitoria y el Derecho de gentes, A. DE LA HERA, "La ética de la Conquista de América en el pensamiento de europeo anterior a Vitoria", $\mathbf{L a}$ Ética en la Conquista... [6]; PEREÑA, "El concepto ..." [8] y "Respuestas universitarias a la duda indiana", La Ética en la Conquista... [6].

12 ZaVAla, [8], p. 23 y cap. 1. 
a los dramaturgos, que se dirigían a un público popular y amplio para transmitir la ideología más acorde con los intereses del Poder ${ }^{13}$.

Sobre las tablas de los corrales la justificación de la Conquista que se manifestaba para el público era la que se apoyaba en la propagación de los ideales religiosos, puesto que la monarquía española era la paladina del catolicismo. La literatura barroca realizaba la identificación entre los conceptos de $\mathrm{Fe}$ - Religión - Bien - Iglesia España - Una - Católica en un discurso cerrado que se autojustificaba remitiéndose a la tradición y la historia nacionales, en el que la unidad religiosa se veía como el mejor modo para mantener la cohesión social y la unidad política del país ${ }^{14}$, porque al elegir la dimensión de la fe, se establecía inmediatamente una conexión con los sentimientos populares $\mathrm{y}$, a la vez, se suspendía sobre quienes se hubieran atrevido a criticar la Conquista la sombra y la amenaza de la acusación de heterodoxia: para difundir la leyenda negra ya había bastante con los herejes extranjeros, y es probable que por esa razón algunos escritores del Siglo de Oro mantuvieran un prudente silencio sobre ese asunto, porque, al no poder enjuiciarlo, preferían ignorarlo o reinterpretarlo. Por ejemplo, la codicia de los conquistadores no era un misterio para nadie en España durante los siglos XVI y XVII, pero su modo de actuar y las atrocidades que estaban cometiendo se justificaban en nombre del fin evangélico que se proponían. Se trata de un mecanismo de persuasión ideológica que se ha visto en acción también en nuestro siglo al tratar de valorar y exaltar ciertos regímenes políticos. Y en la cultura del Barroco era natural que el soberano tuviera todo el interés del mundo por presentarse como defensor de la fe.

Lo había dicho ya Palacios Rubios al hacer del monarca el instrumento de la Providencia:

13 Sobre la cultura política de la época, H. BAADER, "La Conquista de América en la literatura española", Romanische Forschungen, 2-3, 1978; J.M. DIEZ BORQUE, Sociedad y teatro en la España de Lope de Vega, Barcelona, 1978 y Sociología de la comedia española del siglo XVII, Madrid, 1979; J. A. MARAVALL, La cultura del barroco, Barcelona, 1977, y Utopía y reformismo en la España de los Austrias, Madrid, 1982; Teatro y literatura en la sociedad barroca, Barcelona, 1990; T. TODOROV, La conquête de l'Amérique. La question de l'autre, Paris, 1982.

14 G. GonZÁlez, Drama y teología en el Siglo de Oro, Salamanca, 1987. 
No hay riquezas, tesoros, honores ni bienes en este mundo superiores á la Fe Católica, que salva á los pecadores. Conveniente es, por tanto, que la Iglesia Católica brille y se difunda por el mundo entero por obra de un Rey Católico y con ayuda del pueblo, el cual refunde en Cristo todas las cualidades de un piadosísimo príncipe.

Ramos $^{15}$ ha analizado este ejercicio de retoque de la empresa americana alegando que no se podía hablar con rigor de Conquista porque "no estaba prevista y, por tanto, no se programó". Las medidas que tomó la Corona lo fueron "para salir al paso de las situaciones de sorpresa". En cambio a partir de 1534 el soberano habría tomado las riendas de la situación para imponer su punto de vista orientado principalmente a la propagación de la religión. Por lo tanto el rey, la más alta autoridad, armonizaba el esfuerzo de todas las instancias sociales en un clima cultural y político de consenso impuesto por una ideología emanada directamente desde el Poder. Es importante insistir en que la finalidad del mensaje ideológico consistía en retocar la realidad, intentando hacer olvidar los aspectos más oscuros de la Conquista, aquéllos que eran precisamente los que representaban la negación del humanismo cristiano que la propaganda oficial iba proclamando. Desde un principio las empresas de conquista se habían emprendido bajo forma de iniciativas privadas, en busca del máximo beneficio económico y la Duda Indiana había significado "plantearse la validez de lo que constituía la raíz y el fundamento de un grupo social, los conquistadores, que defendían a brazo partido sus intereses frente al creciente regalismo de la Corona". Además es muy importante notar el alcance económico y social de las disposiciones reales, porque, como ha dicho Lohmann Villena, "las Leyes Nuevas herían de muerte la conciencia señorial de la nueva clase social surgida en el Nuevo Mundo, y aniquilaban prácticamente la columna vertebral de la economía privada [...]. De esta suerte, los colonos sin excepción se consideraban defraudados en las

15 Palacios Rubios, [11], p. 3; Ramos, [10], p. 131. Huelga insistir, por bien sabida, en la idea del Príncipe Cristiano de los tratados de la Contrarreforma. Sobre este particular son interesantísimas las observaciones de H. MÉCHOULAN en la Introducción a F. FURIó CERIOL, Concejo y consejeros del príncipe, Madrid, 1978, pp. 79-81 y passim y Q. ALDEA VAQUERO, "Iglesia y Estado en la época barroca", Historia de España, [3]. Para los aspectos del mesianismo renacentista, véanse M. MiguÉLEZ, "Fray Luis de León y el descubrimiento de América", Ciudad de Dios, 30, 1893, ElliotT, [4]; D. KADIR, Columbus and the end of the Earth, Berkeley, 1992. 
expectativas que habían cifrado al enrolarse en las huestes conquistadoras, y daban por descontado que serían víctimas de una confiscación de feudos granjeados legítimamente"16, lo que era precisamente el sentir de Carvajal en Amazonas en las Indias.

Para algunos autores el sentido último de las Leyes Nuevas de 1542 habría sido poner coto a la desmesurada codicia de los españoles en América al subordinarlos a la autoridad de la Corona para impedir que siguieran teniendo lugar las atrocidades que nadie negaba se habían cometido durante el proceso de sometimiento de los pueblos vencidos. La gran diferencia en el planteamiento del problema es que, hasta la regulación definitiva de las problemáticas relaciones entre nativos y europeos, se reconocían abiertamente las injusticias y los desafueros, aunque sólo fuera para condenarlos; en cambio, la propaganda política que empezó a actuar con el teatro nacional del siglo XVII efectuaba una remoción del pasado y una reescritura de la historia tendentes a imponer la idea de una Conquista pacífica y amable centrada sólo en la preocupación por la salud de las almas de los nativos. Por ello la fecha de la Ordenanza de 1573 se puede tomar también como el momento inicial del nuevo clima político y cultural.

\section{VALORACIÓN POLÍtica DE LAS LEYES NuEVAS EN TIRSO DE MOLINA}

Es ahora cuando se puede volver a Tirso y al problema del significado de su obra, pues su posición es muy interesante. En cuanto escritor y dramaturgo, participó en primera persona en la formación del clima literario del Siglo de Oro español, y en cuanto propagandista de la sociedad de la Contrarreforma sus obras son una importante aportación a la formación de la alienación ideológica fomentada desde el Poder. Por la fecha de las obras, objeto de este estudio, Tirso se alejaba enormemente del calor de la polémica sobre la encomienda, y sin embargo en su Trilogía el autor introducía reflexiones y puntos de vista que parecían querer abrir viejas heridas, y esto

16 Zavala, Los intereses particulares en la Conquista de la Nueva España, México, 1964; GonZÁleZ RodríGueZ, [8] p. 273; G. LOHMANN VILLENA, "Las Leyes Nuevas y sus consecuencias en Perú", Historia General de España y América, VII, Madrid, 1982, p. 417. También LucenA, [8], y Fernández Herrero, [7]; J.M. PÉrez Prendes, "La solución legal de la «Duda Indiana»", La Ética en la Conquista... [6]. 
es lo más asombroso, puesto que en todo el texto la constante temática y el fin declarado eran la voluntad de limpiar el nombre de los Pizarro de la acusación de traición y rebelión a la vez que reivindicar el marquesado de la Conquista para los descendientes de Francisco. En este sentido, Tirso debería haber elaborado su Trilogía desde un punto de vista argumental de alabanza al Poder y a la discreción política que lo ejerció, pero el dramaturgo también tenía otros fines, por lo que su obra adquirió un significado distinto y menos inocente de lo que cabría esperar.

La ambigüedad de la posición tirsiana se hace más comprensible si se la enmarca en la situación política del gobierno de España y las Indias en la edad de los Austrias menores: entre 1550 y 1620 el proceso de sistematización del gobierno americano constó de tres fases, ascendente la primera con preocupaciones humanísticas hasta cerca de 1570 -la que Tirso pretendía borrar literariamente, otra de apogeo de la construcción de los reinos americanos, entre 1570 y 1590 , y la lenta decadencia pero cada vez más pronunciada entre 1595 y 1620 , es decir, un momento que fue un período en el que empezaron a surgir dudas sobre el sentido y el valor del imperio español y el modo en que se lo estaba gobernando ${ }^{17}$. Tirso de Molina escribía sobre América en un momento concreto en el que la corrupción y la incapacidad de gobernar rectamente el Nuevo Mundo se estaban poniendo de manifiesto, y no quería ser neutral, cosa muy explicable dada su oposición al conde-duque; por eso defendía los derechos de los primeros conquistadores, que eran quienes habían asegurado las Indias para la corona, recibiendo en pago daño y desdén. Desde ese punto de vista, mirar hacia atrás en 1626 significaba que el mensaje de la Trilogía consistía en sostener que los encomenderos eran tanto o más capaces de regir el Nuevo Mundo que los nuevos órganos de gobierno que Olivares estaba creando, y las tres comedias adquirían valor de propuesta política concreta, porque (re)proponían el modus operandi del viejo conquistador al abogar por la rehabilitación del traidor Pizarro.

17 G. CÉSPEDES DEL CASTILlo, “América Hispánica", Historia de España, de, M. TuÑóN DE LARA, VI, Barcelona, 1983, pp. 100 y ss. El proceso de formación de la administración indiana se puede encontrar descrito en ELLIOTT, "España y su imperio en los siglos XVI y XVII", [4], I, y pp. 46 y ss. 
Así, la obra tirsiana no era sólo un encargo individual de la familia Pizarro, sino también la defensa de una clase social en su conjunto y de una organización socio-política, la estamental feudal. Una vez más, al encontrar una carga ideológica explícita, se justifica la lectura política de la Trilogía. Ya lo hizo notar Elliott: cuando el mensaje ideológico conservador, fundado en la expansión y preponderancia de la religión, exalta a los grupos sociales en ese momento no favorecidos, entonces tiende a entrar en conflicto de intereses con el poder de la Corona $^{18}$, y en las fechas del texto tirsiano se daban esas circunstancias.

Varios hechos de política americana avalan esta afirmación. En 1601 se suspendieron los repartimientos para las tareas agrícolas, estableciendo en su lugar un teórico trabajo libre pagado; con la Real Cédula 3/VI/1609, se retocaban los servicios forzosos, permitiéndolos de nuevo pero con reformas y exclusiones; en 1629 otra Real Cédula obligaba a los encomenderos al servicio de armas en las zonas de mayor necesidad militar... Además los religiosos estaban viendo que se levantaban muchos obstáculos para desarrollar su trabajo misional en América, a causa de la relativa independencia del poder político que tenían, y cuyo extremo sería el episodio de los jesuitas en Paraguay. En la primera mitad del Seiscientos el clima político estaba tal vez enrarecido al punto de que el P. Izquierdo escribió el Memorial a la Reina para protestar por la prohibición de pasar a las Indias hecha en 1647 a los jesuitas extranjeros, por lo que Izquierdo exigía de la Corona que cumpliera sus deberes de evangelizar el Nuevo Mundo -retomaba de nuevo las argumentaciones de los escritores que justificaban la Conquista en el siglo precedente en base a consideraciones religiosas, y ésa era exactamente la idea que tenía también Tirso de Molina sobre los deberes de un buen rey. Sobre este punto sus ideas eran muy ortodoxas y estaban perfectamente en línea con las de Palacios Rubios.

\footnotetext{
18 ElliotT, "Poder y propaganda en la España de Felipe IV", [4]. También es muy interesante J.A. MARAVALL, La oposición política bajo los Austrias, Barcelona, 1974.
} 


\section{LA TRILOGÍA Y EL IDEARIO POLÍTICO DE TIRSO DE MOLINA.}

En la Trilogía la figura del soberano recibe, paradójicamente, críticas y alabanzas a la vez: el rey es el deus ex machina que hace justicia en la persona de Fernando Pizarro, pero las desventuras de la familia y la guerra civil en Perú en buena medida habían sido causadas por la política del emperador, demasiado inclinado a prestar oídos a sus consejeros a propósito de las Leyes Nuevas. El mensaje principal del texto es que si el emperador se ha equivocado, la culpa la tuvieron sus consejeros, o las juntas, en suma quienes se arrogaban la facultad de intervenir en la conducción de los asuntos del Estado.

En Amazonas en las Indias, la segunda comedia de la Trilogía, la acción se desarrolla en Perú, durante las guerras civiles entre Pizarro y Almagro. En medio de la línea dramática, Carvajal se lamentaba de la política del emperador, tachándola de capricho, arbitrio, invención de ociosos. Se podrá argüir que esas palabras eran obligadas para reflejar un clima histórico, y que la verdad forzaba a Tirso a escribirlas, pero aún así se puede intentar averiguar si reflejaban sólo la opinión de Carvajal y Pizarro o también la del autor. Sea como fuere, eran opiniones que no podían agradar demasiado a los oídos cortesanos, o del mismo Felipe IV, descendiente de los monarcas tan duramente criticados en la comedia, lo que parecería un error estratégico de Tirso, puesto que si quería reivindicar el buen nombre y el honor de la familia Pizarro, hubiera debido intentar asegurarse la benevolencia del Poder. Entonces lo que habría que ver es si el objetivo final de Fray Gabriel Téllez no sería más bien el de remachar una idea con fines de propaganda, haciendo leva en el sentimiento difuso de oposición al régimen de los validos, aprovechando y a un tiempo fomentando un estado de opinión. En este sentido, se trataría de una acción de agitación político-cultural de clara oposición, y para ello Tirso no dudaba en descalificar la labor humanitaria de tutela de los derechos de los indios realizada por los frailes en la primera mitad del siglo anterior.

Parece increíble que un hombre de la Iglesia se atreviera a criticar en términos tan tajantes los esfuerzos humanitarios que ochenta años antes habían animado a otros religiosos, desde Montesinos hasta Las Casas, Motolinía, De Paz... que habían defendido a los indígenas en nombre del Evangelio. Ahora bien, durante el Siglo de Oro la situación política y cultural en España había evolucionado tanto que 
para la Iglesia Pizarro era "un bendito hombre" mientras que para Las Casas "conquistó y destruyó"19, pero esto era así para la Iglesia de la Contrarreforma, la del tiempo de Tirso, no para la Renacentista. De nuevo Tirso actuaba con un doble objetivo, porque pretendía acallar las voces contrarias a los hechos de los Pizarro desmontando sus acusaciones a propósito de la encomienda e implícitamente emparejaba los errores de antaño con los de hogaño.

Este análisis se justifica porque el tema de la encomienda se introduce inmediatamente en el segundo acto de Amazonas, justo tras la derrota de Diego de Almagro. Vaca de Castro hablaba con Carvajal a propósito de la merecida recompensa que el César concedería sin duda a sus fieles servidores, y entre los favores a los conquistadores no podrían faltar las encomiendas:
Esto es cierto, como lo será también el premiar su Majestad el valor y la lealtad de los que firmes estén en su servicio; y yo agora, en su nombre agradecido, honraré a cuantos han sido de nuestra parte: no ignora el noble merecimiento a fuer de la sangre ingrata. Todo este imperio de plata, indios y repartimientos no pueden satisfacer lo mucho destos empeños: pero llamándoos sus dueños tendrán menos que temer. (968-984).

Incluso se decía que la encomienda no era suficiente para recompensar a los conquistadores; pero era lo único que se podía hacer... En el acto tercero, cuando Gonzalo Pizarro rechazaba el reino del Perú:

19 ToRres Nebrera, "Introducción", a Tirso de Molina, Hazañas de los Pizarro, Mérida, 1993, p. 13; W. COHEN, Drama of a nation, Ann Arbor, 1983; P. JAURALDE, "El público y la realidad histórica de la literatura española de los siglos XVI y XVII", Edad de Oro, I, 1982.

R. I., 1997, n. $^{\circ} 210$ 


\author{
con ellos premios reparta \\ quien a perseguirnos viene \\ déle indios, déle plata \\ (3113-3115).
}

Se reconocía abiertamente el móvil económico y el interés personal en la Conquista y, más allá de ésta, en toda acción política. Los conquistadores entendían la encomienda de manera más material y prosaica de lo que hacían sus teóricos defensores, interpretándola - correctamente, por desgracia - como la propiedad de una mano de obra por explotar en beneficio propio. Así lo declaraba el mismo Gonzalo Pizarro cuando decidía retirarse de la vida política activa tras la expedición al País de la Canela y mientras esperaba que el emperador recompensara sus servicios:

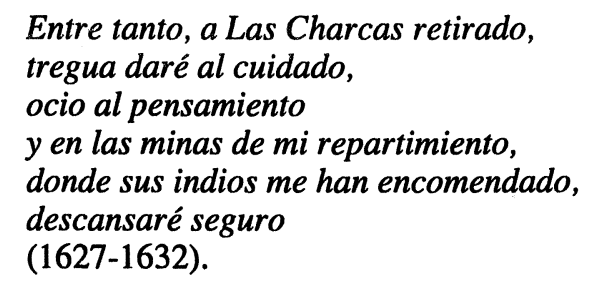

Aparentemente, en su forma, estas expresiones sólo eran la formulación del tema clásico del beatus ille mil veces repetido, pero aquí conviene recordar que el héroe no se retiraba al campo a cavar el huerto con sus manos sino a gozar de los frutos del trabajo de sus indios encomendados. Gonzalo Pizarro, patrón y explotador de trabajadores, era para Tirso de Molina el modelo del conquistador reciclado a protoempresario, y cuando Carvajal introduce en la comedia el sentimiento profundo de haber sido engañado que era de todos los conquistadores tras la proclamación de las Leyes Nuevas por parte de Blasco Núñez, acusa al emperador de que "quiere perderse y perdernos por no humanarse y oírnos" (Amazonas, II, vv. 1944-1945). Y para los encomenderos perderse quería decir no poder seguir disfrutando de su posición privilegiada conseguida gracias al dominio directo sobre los indios. Tanto es así que Tirso, para defender y justificar a Gonzalo Pizarro de la acusación de traición y rebelión, explicaba en La Lealtad contra la envidia la situación de su personaje a raíz de 


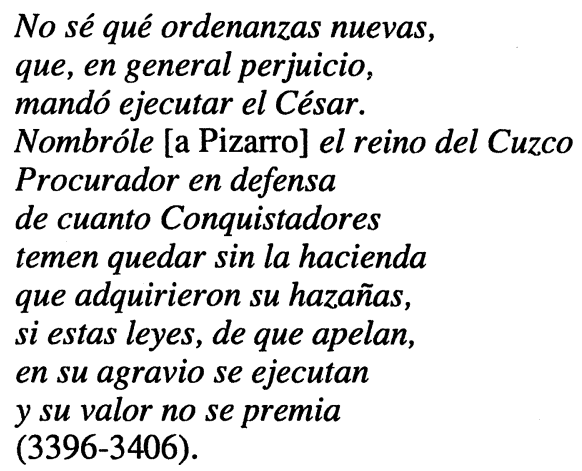

Tirso estaba proponiendo dos cosas. La vuelta a la mentalidad medieval feudal originada directamente en la Reconquista y que consistía en premiar antes con feudos a los vasallos más fieles, y ahora a los conquistadores del Nuevo Mundo, y también el control directo, personal, de los gobernados por parte de los gobernantes, para asegurar la presencia española en América. Ambas ideas se recuperaban de la tradición del pensamiento político medieval, pero es difícilmente creíble que pudieran llevarse a la práctica en el clima instaurado por el gobierno de Olivares ${ }^{20}$.

Por lo tanto está claro que en 1626 el fraile mercedario no era el portavoz del indio, de la sociedad utópica del Renacimiento ${ }^{21}$, sino del europeo, y de un país que estaba gravemente marcado por una crisis que lo obligaba a mantenerse a la defensiva. Sin el encomendero

\author{
Nuestra ley (cuyos principios \\ saben los Indios apenas) \\ podrá en esto ser mudable, \\ si en su libertad los dexan. \\ Aun viviendo encomendados \\ a Españoles (que refrenan \\ su superstición ar tigua, \\ y nuestra Fe les enseñan) \\ buscan de noche las Guacas
}

20 Sobre el significado de la aristocratización en la época de los validos, véanse C. PÉrez Bustamante, "La España de Felipe III", Historia de España, dir. R. MEnÉndez PIDAL, XXIV, Madrid, 1983, cap. XX, pp. 417 y ss. y F. TOMÁS Y VALIENTE, "Las instituciones situadas en el ámbito de la monarquía", Historia de España, [3], pp. 107 y 116-117.

21 J.A. Maravall, Carlos $V$ y el pensamiento político del Renacimiento, Madrid, 1960, y [13].

R. I., $1997, \mathrm{n}^{\circ} 210$ 


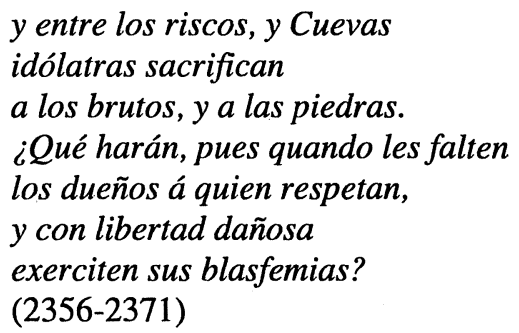

Ahora no cabían las consideraciones humanitarias sino que había que cerrar filas en una cultura beligerante y por lo tanto en una sociedad rígidamente estamental. Lo que hacía Tirso era recordar los méritos de los Conquistadores de antaño pero con razones que eran actuales también en su época:

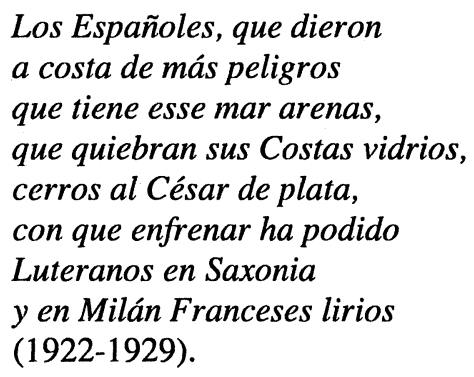

Era la continuación del discurso de Carvajal, y ahora se dejaban claros los datos del asunto: la Corona actuó mal con los encomenderos porque gracias a éstos el emperador había podido luchar con los protestantes y con los franceses. Dicho de otra manera, el rey debía sus posesiones en América y en Europa a los conquistadores injustamente penalizados, y Tirso de Molina decía eso alabando a un personaje que se había levantado contra su legítimo señor. Desde luego parece una manera poco común de exaltar la memoria de un vasallo, pero en la realidad el dramaturgo buscaba que el Poder otorgara sus favores a quienes habían hecho posible que ese mismo Poder aún estuviera vigente. A la Corona, recordando a quién debía el oro que financiaba su prestigio, a la Iglesia recordando a quien había llevado la fe al Nuevo Mundo. Por oposición, es evidente que quienes amenazaban al poder eran quienes, en tiempos de Tirso, introducían novedades en el gobierno igual que un siglo antes habían introducido 
otras novedades en la legislación americana, y cuyos resultados Tirso desplayaba ante los ojos de todos.

La relación con los indios había dado una vuelta de 180 grados y el valor de metatexto ideológico de la Trilogía es evidente en la justificación que aceptaba el intelectual barroco. El encomendero era el pilar de la sociedad americana porque se la pintaba igual de amenazada en su religión que se pintaba a la europea; allende en mar la idolatría, aquende los protestantes. Y en este marco político y cultural los nativos americanos eran eternamente menores de edad, si no es que incluso perversos. La función del europeo era la de guiarlos, en un planteamiento perfectamente colonialista ante litteram. Como iba dirigido a un público popular, además, el mensaje ideológico contribuía a formar y mantener viva una actitud de aceptación acrítica de la historia más reciente. La singularidad de Tirso es que otros autores del Barroco - sobre todo Lope de Vega y Calderón de la Barca- desarrollaron un mensaje ideológico nacionalista y conservador en sus obras, pero solamente el mercedario se atrevió a atacar frontalmente las leyes humanitarias que la Corona había dictado. A pesar de que el dramaturgo se apoyaba en hechos históricos, su análisis era muy sesgado porque, para defender los intereses de sus patronos, tenía que criticar la política de los reyes de Castilla. Esto a su vez entraba en conflicto con la cultura y la ideología de consenso nacionalista que Tirso defendía por encima de cualquier otra consideración.

\section{OPOSICIÓN Y CRÍTICA EN LA TRILOGÍA.}

"Pudo haber un teatro de oposición" con Tirso, en su Trilogía, como ha dicho Elliott ${ }^{22}$. Intentaremos por tanto exponer algunas evidencias textuales de la postura tirsiana y el mensaje ideológico bifronte de su obra: por una parte la mera búsqueda del reconocimiento histórico del buen nombre de los Pizarro, por otra también una intervención indirecta en la discusión política y en la coyuntura de su tiempo.

22 Kennedy, [1], pp. 16-17, 46, 52-53, y ElliotT, Poder... [4], p. 221. Tanto más cierto en cuanto que, al parecer, una vez pasados a la oposición, los Pimentel se deleitaban con representaciones privadas de obras tirsianas cuyo blanco era el Conde-duque, ELLIOTT, [2], p. 315.

R. I., 1997, n. $^{\circ} 210$ 
De los tres títulos es Amazonas en las Indias el más político en cuanto que tocaba una materia directamente relacionada con el gobierno y las consecuencias de las acciones políticas justas o injustas. Ya en la escena, desde los primeros versos, una de las dos amazonas, Menalipe, tiene buen cuidado en contraponer la grandeza y la lealtad de los hermanos Pizarro a la bajeza y las intrigas de los consejeros en la corte (537-548). El retrato de Gonzalo no ofrece lugar a dudas, desde el primer momento, acerca de su lealtad. La amazona le ofrece la mano, con lo que podría convertirse en rey de las Indias, pero el español la rechaza diciendo que

\section{Si te doy la mano agora tendrá la envidia ocasión de afirmar que me levanto contra mi rey, con la tierra (645-648).}

Por mucho que fuera un lugar común, es el ejemplo de la distancia social y moral entre el soldado y el cortesano. Se puede leer todo el texto, justificadamente, como la denuncia de los consejeros indignos de la confianza de su señor. Es lo que ocurre en la larga tirada de Menalipe al prevenir a Pizarro de quienes lo alababan y aconsejaban movidos exclusivamente por su interés personal:

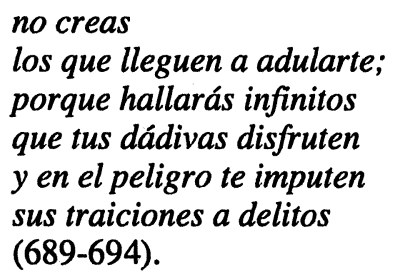

En la visión política de Tirso, la relación ideal era la directa, personal, feudal, entre vasallo y señor. La presencia de intermediarios, ya fueran ministros, virreyes, consejos o validos, rompía la armonía del orden de gobierno e introducía un elemento de desequilibrio que sólo podía desembocar en catástrofe, y de hecho en la Trilogía las acciones más desastrosas siempre tienen su origen en la intervención de un tercero que influye en uno de los dos campos con el fin de precipitar la situación. Así ocurría con la publicación de las Leyes 
Nuevas bajo el mandato de Núñez Vela, y los compañeros de Pizarro - los malos consejeros - insistían para que éste hiciera valer los derechos de los conquistadores encomenderos, aunque el héroe se negara a ello y se retirara a Las Charcas

\author{
mientras el Emperador \\ no derogue el dominio \\ que, en daño de mi derecho, \\ han negociado validos \\ para Blasco Núñez Vela \\ (1990-1994).
}

Los consejeros imprudentes intervenían para forzar la acción, para abolir las encomiendas, para quitar el gobierno a los conquistadores; pero por el bando pizarrista también había quien aconsejaba mal. Carvajal, por ejemplo, al criticar a Gonzalo Pizarro y echarle en cara la decisión de retirarse a su hacienda, ciertamente no demostraba prudencia:

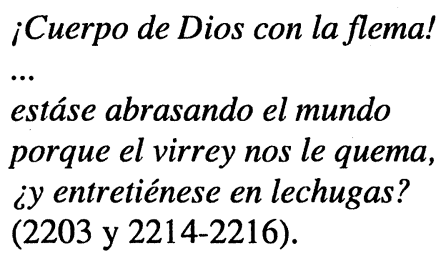

Inmediatamente después del ex abrupto de Carvajal era Almendrales quien invitaba a Pizarro a que se proclamara gobernador de Cuzco contra Núñez Vela, pero no lo hacía en nombre de los derechos de los encomenderos - pues sería políticamente incorrecto, dado el fin de la Trilogía - sino afirmando que Pizarro debería actuar para enderezar los entuertos causados a los derechos legítimos de los conquistadores por las tramas oscuras de quienes maquinaban - es decir, aconsejaban - en la sombra. De nuevo el papel nefasto de los malos consejeros puesto al descubierto por Tirso a través de sus personajes (2232 ss.), y de nuevo en el bando contrario los malos consejeros eran quienes querían empujar a Gonzalo a aceptar la corona del Perú, cometiendo un acto de felonía que en la comedia el protagonista se negaba a cometer (III, vv. 3091-3157).

R. I., 1997, n. 210 
La crítica del Poder injusto o ejercido injustamente también se manifiesta en el último título de la Trilogía, La lealtad contra la envidia, en el que se narran los tristes avatares de Fernando Pizarro víctima precisamente de la envidia de sus enemigos. Hacia el final de la comedia el soberano hacía justicia, pero hasta ese momento los malos consejeros del emperador habían conseguido que encarcelaran al conquistador adulandolal César, ¡ciegos engaños! (2871-2872).

Sin embargo en el texto tirsiano la figura del consejero era un recurso que se usaba también para sugerir e indicar la actitud que al autor le parecía correcta, de tal modo que el personaje que mal se portaba podía en ocasiones tener ideas buenas. Por ejemplo, una vez estallado el conflicto, y cuando Pizarro salía vencedor, Carvajal, en Amazonas en las Indias, intervenía de nuevo ante Gonzalo, pero esta vez los consejos que le daba eran los correctos, según Tirso, para asegurarse el amor de sus gobernados:

haz títulos, cubre grandes/ [...] lobliga con intereses/ nombra condes y marqueses (2298 y 3001-3002).

Los súbditos, tratados con paternalismo, estarían dispuestos a perder diez mil vidas si supieran que los esperaba la recompensa de su señor, viéndose el bien nacido / como merece premiado (3032-3033), es decir que proponía una política de aristocratización fundada en el peso de los hidalgos, y que debía sonar a crítica de la que estaba realizando el conde-duque favoreciendo la alta nobleza.

La lealtad contra la envidia, leída como mensaje político, contraponía el vasallo fiel y honrado - Francisco Pizarro- a sus enemigos, que eran siempre cortesanos faltos de cualquier valor militar, sin ninguna hazaña que los elevara. Ahora se manifestaban los perniciosos efectos de la adulación al monarca por parte de los malos consejeros, pues hacían peligrar su equidad y su recto sentido del gobierno. En el caso de Pizarro Felipe II abría una puerta a la esperan$\mathrm{za}$, pues rigores severos usal hasta que se informe bien (2902-2903) porque en realidad estaba engañado por los embustes de sus cortesanos. La tarea del buen rey era la de informarse bien sobre la verdad de los casos de gobierno para no ser la presa de los intrigantes, para quienes

la mentira aduladora satisface obligaciones 


\title{
$y$ afectando sentimientos disfraza con cumplimientos, [está] por decir traiciones (2931-2935).
}

Naturalmente, dado que se trataba de una comedia, debía triunfar el bien, con la derrota de los malos consejeros: Mercado anunciaba a Fernando Pizarro que

\author{
Filippo prudente, santo, \\ a pesar de las malicias \\ de vuestros perseguidores, \\ cuanto más os fiscalizan, \\ conoce vuestras lealtades \\ (4044-4048).
}

Los malos consejeros traicionaban a su señor porque no le permitían reconocer y premiar a quienes habían padecido para afirmar su poder. El orden y la armonía del principado cristiano se habían perdido, y sólo podían recuperarse con un cambio en el modo de gobernar. Eso es lo que exclamaba Pizarro, y también el autor:

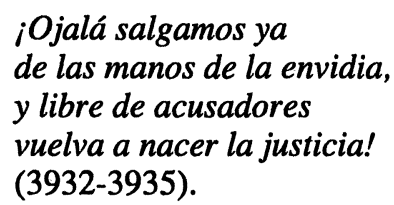

Aquí Tirso hablaba de la justicia en sentido genérico, como principio ideal de gobierno, pero en la Trilogía tenía ocasión de enfocar el problema desde aspectos concretos gracias al asunto de la historia y el fin que se proponía. En el texto pedir justicia era reivindicar la figura de los Pizarro. Y esa defensa había de realizarse denunciando las injusticias que habían sufrido, ellos y sus compañeros conquistadores. La causa? Las interferencias de los consejeros, ispirados por la envidia, en la práctica política del soberano.

En conclusión, en la Trilogía el tono político está siempre presente y el tema de la encomienda es central en el razonamiento tirsiano porque era el que le permitía conectar el pasado con el presente, la parte del texto escrito por encargo y el mensaje de crítica 
política contemporánea para corregir la situación de España. Todo el mensaje ideológico del texto, dadas las características culturales y políticas de la época, se desarrolla de manera indirecta y velada, aunque no por eso era - y es - menos evidente: la encomienda, que era un sistema señorial de gobierno, era la forma más justa y sensata, y fue abolida causando gravísimos problemas no sólo a los conquistadores sino a la Corona; es decir, pérdidas económicas para los unos y desórdenes políticos y guerras civiles para la otra. Y lo que Tirso deseaba recordar es que todo ese mal se debía atribuir a la obra de las juntas, comisiones, a los arbitristas, que habían emprendido la tarea de querer guiar la política regia. El consejero, el cortesano, el valido: he aquí que Tirso de Molina apuntaba hacia los verdaderos peligros, hacia quienes querían introducir novedades y engañaban al monarca.

In the text of Tirso's Trilogía de los Pizarro elements are to be found which allow to affirm that the playwright availed himself of an occasional commission to make an instrument of political criticism aiming at false advisers and validos. Tirso fought against the novelties in the government and policy of the Indies and stood for the abolition of the humanitarian measures of the Leyes Nuevas and the strengthening of the encomenderos' power. Thus the Trilogy presents itself as a telling instance of the mental shift between Renaissance erasmism and the crisis of the Counter-Reformation. 